\title{
Sclerostin is an independent risk factor for all-cause mortality in kidney transplant recipients
}

\author{
Shufei Zeng ${ }^{1,2} \cdot$ Torsten Slowinski $^{1} \cdot$ Wolfgang Pommer $^{3} \cdot$ Ahmed A. Hasan ${ }^{2,4} \cdot$ Mohamed M. S. Gaballa $^{2,4,5}$. \\ Yongping $\mathrm{Lu}^{2,6} \cdot$ Bernhard K. Krämer ${ }^{2} \cdot$ Berthold Hocher ${ }^{2,7,8,9}$ (])
}

Received: 11 February 2020 / Accepted: 7 August 2020 / Published online: 20 August 2020

(c) The Author(s) 2020

\begin{abstract}
Background Sclerostin is a hormone contributing to the bone-vascular wall cross talk and has been implicated in cardiovascular events and mortality in patients with chronic kidney disease (CKD). We analyzed the relationship between sclerostin and mortality in renal transplant recipients.

Methods 600 stable renal transplant recipients (367men, 233 women) were followed for all-cause mortality for 3 years. Blood and urine samples for analysis and clinical data were collected at study entry. We performed Kaplan-Meier survival analysis and Cox regression models considering confounding factors such as age, eGFR, cold ischemia time, HbA1c, phosphate, calcium, and albumin. Optimal cut-off values for the Cox regression model were calculated based on ROC analysis. Results Sixty-five patients died during the observation period. Nonsurvivors ( $n=65$; sclerostin $57.31 \pm 30.28 \mathrm{pmol} / \mathrm{L}$ ) had higher plasma sclerostin levels than survivors $(n=535$; sclerostin $47.52 \pm 24.87 \mathrm{pmol} / \mathrm{L})(p=0.0036)$. Kaplan-Meier curve showed that baseline plasma sclerostin concentrations were associated with all-cause mortality in stable kidney transplant recipients $(p=0.0085$, log-rank test). After multiple Cox regression analysis, plasma levels of sclerostin remained an independent predictor of all-cause mortality (hazard ratio, 1.011; 95\% CI 1.002-1.020; $p=0.0137$ ).

Conclusions Baseline plasma sclerostin is an independent risk factor for all-cause mortality in patients after kidney transplantation.
\end{abstract}

Keywords Kidney transplantation $\cdot$ All-cause mortality $\cdot$ Sclerostin

Electronic supplementary material The online version of this article (https://doi.org/10.1007/s10157-020-01956-y) contains supplementary material, which is available to authorized users.

Berthold Hocher

berthold.hocher@medma.uni-heidelberg.de

1 Department of Nephrology, Charité-Universitätsmedizin Berlin, Campus Mitte, Berlin, Germany

2 Fifth Department of Medicine (Nephrology/Endocrinology/Rheumatology), University Medical Centre Mannheim, University of Heidelberg, Heidelberg, Germany

3 KfH Kuratorium für Dialyse und Nierentransplantation e.V., Bildungszentrum, Neu-Isenburg, Germany

4 Institute of Nutritional Science, University of Potsdam, Potsdam, Germany

\section{Introduction}

Kidney transplant recipients are a subset of patients with chronic kidney disease (CKD). And kidney transplantation is the treatment of choice for end-stage renal disease [1].

5 Faculty of Veterinary Medicine, Benha University, Moshtohor, Toukh, Egypt

6 Department of Nephrology, The First Affiliated Hospital of Jinan University, Jinan University, Guangzhou, China

7 Institute of Medical Diagnostics, IMD Berlin, Berlin, Germany

8 Key Laboratory of Study and Discovery of Small Targeted Molecules of Hunan Province, School of Medicine, Hunan Normal University, Changsha, China

9 Reproductive and Genetic Hospital of CITIC-Xiangya, Changsha, China 
Chronic kidney disease-mineral bone disease (CKDMBD) is associated with increased morbidity and mortality among patients undergoing hemodialysis. Several markers of bone formation and turnover, including fibroblast growth factor 23 (FGF-23), bone-specific alkaline phosphatase and parathyroid hormone $(\mathrm{PTH})$, have been shown to be associated with increased mortality [2-4]. Vascular calcification has been associated with bone and mineral disorders [5].

Sclerostin (SOST) protein is a 213 amino acid protein transcribed from the SOST gene [6, 7]. It is a soluble inhibitor of the Wnt pathway which promotes bone formation. It is among the recently discovered players of the bone-vascular wall cross talk and has gained increased attention lately. Circulating and bone sclerostin mRNA or protein levels in humans and in mice change in response to factors such as hormonal, systemic, and mechanosensory stimuli. Known regulators of sclerostin include $\mathrm{PTH}$, sex steroids, thyroid hormone, corticosteroids, vitamin $\mathrm{D}$, diabetes mellitus, immobilization/spinal cord injury/weight loss/weightlessness, skeletal loading/exercise, malignancies and renal disease [8]. An interesting clinical study showed that serum levels of sclerostin are associated with an increased risk of cardiovascular events and mortality in patients with CKD [9]. However, to the best of our knowledge, the relationship between sclerostin and mortality in renal transplant recipients has never been reported.

Therefore, we analyzed, whether sclerostin is a risk factor of all-cause mortality in kidney transplant recipients. To control for possible confounding, we performed multivariate Cox regression analyses considering known confounding factors [10-14].

\section{Materials and methods}

\section{Study population}

We analyzed a kidney transplant patient cohort as described recently, for details, see [15]. Six hundred deceased donor kidney transplant recipients ( 367 men, 233 women) were enrolled in a prospective study, which was conducted at the transplant clinic Charite-Mitte, Berlin, Germany, between August and December 2012. The patients gave their informed consent. The study protocol was approved by the local ethical committees (approval number 2012327). Patients were excluded if they had any acute infection, malignancy, acute rejection (patients who have biopsyproven acute rejection within 6 months after transplant), acute myocardial infarction, pulmonary edema, heart failure at the time of blood sampling. At the beginning of the study, blood was collected and stored at $-20{ }^{\circ} \mathrm{C}$ until use. The patients were followed for all-cause mortality for 3 years.

\section{Data sources and measurement}

Demographic data for recipients and donors (cold ischemia time, HLA mismatches, donor's age, panel reactive antibodies, recipient's age and sex, and transplant survival, underlying kidney disease etc.) were extracted from hospital records and the Euro-transplant records of the patients. Albumin, creatinine, cholesterol, $\mathrm{HbA} 1 \mathrm{c}, 1,25(\mathrm{OH}) 2 \mathrm{D}$, calcium, phosphate, $\mathrm{iPTH}$, fasting blood glucose and urinary protein were measured by standardized methods in the central clinical laboratories of Charité. All the used assays were subject to regular quality control. Sclerostin concentration was analyzed with the use of a commercial ELISA (BI-20492, Biomedica Medizinprodukte GmbH, Vienna, Austria), according to the manufacturer's instructions.

\section{Statistical analysis}

We analyzed blood levels of calcium, phosphate, HbA1c, eGFR, albumin, patient age and cold ischemia time using the area under the receiver operating characteristic (ROC) curve to obtain optimal cut-off values for these parameters [16]. When the ROC curve is plotted with 1 -specificity on the abscissa and the corresponding values for sensitivity on the ordinate, the point of the ROC curve closest to the upper left corner of the coordinate system (where sensitivity and specificity equal 1) represents the best cutoff value. These cutoff values were calculated and used to transform individual continuous parameters into binary endpoints.

Plasma levels of sclerostin in survivors and nonsurvivors were compared using independent $T$ test. Survival rates were tested for significant differences with the log-rank test using the Kaplan-Meier method. Univariate Cox proportional hazards modeling was performed to investigate the relationship between clinical measurements and mortality based on previously identified researches [10-14]. To control for possible confounding, we first performed multivariate Cox regression analyses considering age, eGFR, and plasma albumin. Based on these confounding factors, we add plasma calcium and phosphate in model B to test the stability of the independent relationship between sclerostin and all-cause mortality. Furthermore, we considered all parameters that were significant predictors in univariate analysis (age, eGFR, plasma albumin, phosphate, calcium, HbA1c, and cold ischemia time) as confounding factors in model C. In subgroup analysis, we grouped according to the cutoff value of sex, eGFR, phosphate and calcium respectively and performed multivariate Cox regression analysis of model $\mathrm{C}$ in each subgroup. 
Table 1 Clinical data and plasma parameters in all 600 renal transplant recipients at study entry

\begin{tabular}{|c|c|c|}
\hline & Mean (SD) or $n$ & $\begin{array}{l}\text { Median } \\
\text { (interquartile } \\
\text { range) }\end{array}$ \\
\hline Age at study entry (years) & $54.57 \pm 14.54$ & $55.00(22)$ \\
\hline Sex male/female $(n)$ & $367 / 233$ & $367 / 233$ \\
\hline Donor age (years) & $49.37 \pm 15.82$ & $52.00(23)$ \\
\hline Time on dialysis (month) & $49.51 \pm 35.23$ & $48.00(59)$ \\
\hline Time post-transplantation (month) & $89.85 \pm 75.32$ & $60.00(77)$ \\
\hline Cold ischemia time (h) & $10.06 \pm 7.34$ & $9.78(8.88)$ \\
\hline $\mathrm{eGFR}\left(\mathrm{mL} / \mathrm{min} / 1.73 \mathrm{~m}^{2}\right)$ & $44.41 \pm 18.03$ & $43.00(26)$ \\
\hline Plasma albumin (g/dL) & $4.55 \pm 0.35$ & $4.50(0.50)$ \\
\hline Plasma creatinine $(\mathrm{mg} / \mathrm{dL})$ & $1.75 \pm 0.72$ & $1.57(0.75)$ \\
\hline Total cholesterol (mg/dL) & $223.12 \pm 52.96$ & $220.00(77)$ \\
\hline HbA1c (\%) & $5.89 \pm 0.85$ & $5.80(0.80)$ \\
\hline Plasma $1,25(\mathrm{OH})_{2} \mathrm{D}(\mathrm{pmol} / \mathrm{L})$ & $96.17 \pm 54.39$ & $90.00(72.50)$ \\
\hline Plasma calcium (mmol/L) & $2.48 \pm 0.19$ & $2.46(0.22)$ \\
\hline Plasma phosphate (mmol/L) & $0.88 \pm 0.26$ & $0.84(0.31)$ \\
\hline Plasma iPTH (pg/mL) & $113.85 \pm 129.49$ & $85.31(93.12)$ \\
\hline Plasma sclerostin (pmol/L) & $48.58 \pm 25.67$ & $45.90(25.75)$ \\
\hline Fasting blood glucose (mg/dL) & $95.61 \pm 35.10$ & $88.00(32)$ \\
\hline Urinary protein $(\mathrm{mg} / 24 \mathrm{~h})$ & $366.34 \pm 646.56$ & $167.00(212)$ \\
\hline
\end{tabular}

Values are presented as mean (SD) and median (interquartile range) or $n$

eGFR, estimated glomerular filtration rate; HbA1c, hemoglobin A1c; iPTH, intact parathyroid hormone

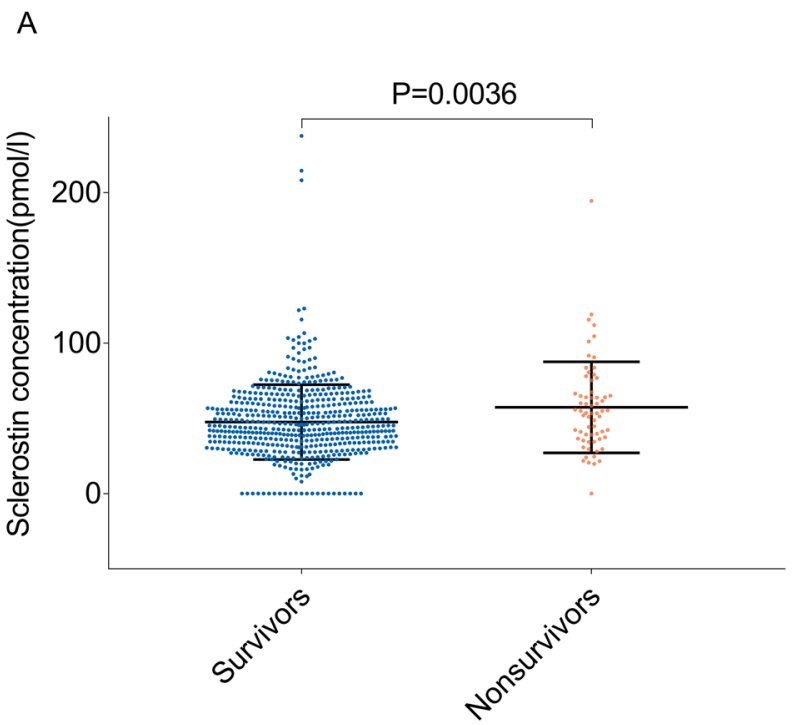

Fig. 1 Differences in plasma sclerostin levels between survivors and non-survivors and survival rates in patients with higher and lower levels of sclerostin. a Individual sclerostin values in patients who died and survived during the follow-up period. b Kaplan-Meier curves, according to mean plasma sclerostin concentration $(48.58 \mathrm{pmol} / \mathrm{L})$,

\section{Results}

A total of 600 stable renal transplant recipients, 367 males and 233 females, aged $20-87$ years, were included in this study. Patient demographics and relevant clinical and biochemical parameters are summarized in Table 1. At study entry, mean age of patients was $54.57 \pm 14.54$ years old, and mean estimated glomerular filtration rate (eGFR) was $44.41 \pm 18.03 \mathrm{~mL} / \mathrm{min} / 1.73 \mathrm{~m}^{2}$. Meantime since transplantation was $89.85 \pm 75.32$ months, and time on dialysis before renal transplantation was $49.51 \pm 35.23$ months. Mean plasma sclerostin concentration was $48.58 \pm 25.67 \mathrm{pmol} / \mathrm{L}$. The concentration of sclerostin was significantly $(p=0.0003)$ higher in male $(51.58 \pm 25.16 \mathrm{pmol} / \mathrm{L})$ compared to female $(43.85 \pm 25.79 \mathrm{pmol} / \mathrm{L})$ patients. Sclerostin concentrations were slightly higher in patients treated with Cyclosporin A versus Tacrolimus treated patients (see supplementary Fig. 1). Sixty-five patients died during the observation period.

The underlying renal diseases are as follows: 474 of the 600 patients had primary renal diseases. Fifty-eight patients had secondary renal disease. In 68 patients, the underlying renal disease was unknown. More than 60 percent of patients had the primary glomerular disease, polycystic kidney disease and interstitial kidney disease. The underlying kidney diseases are described in Supplementary Table 1.

Nonsurvivors had higher plasma levels of sclerostin than survivors (Fig. 1; $p=0.0036)$. Sclerostin concentrations

B

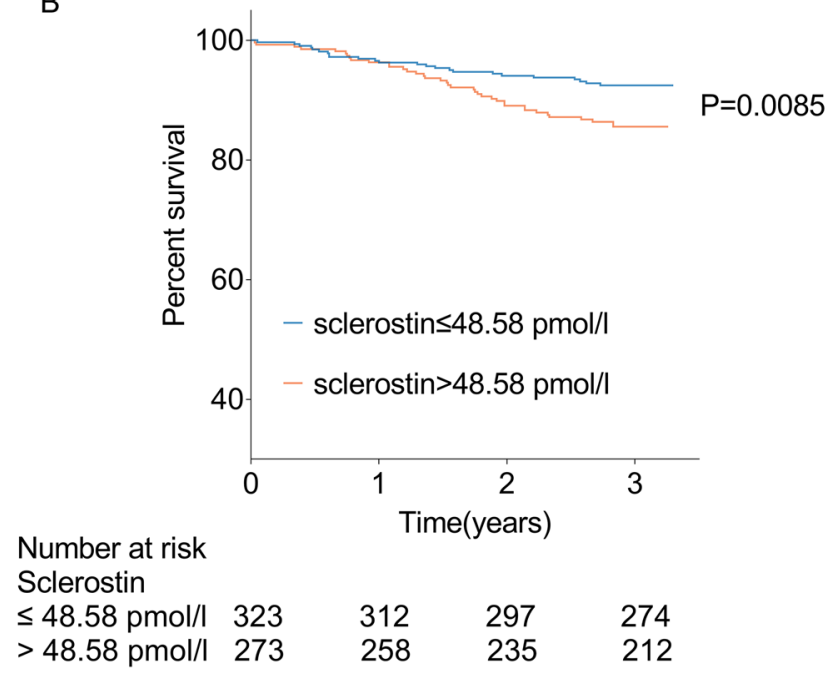

for all-cause mortality. Blue lines, patients with plasma sclerostin levels of $\leq 48.58 \mathrm{pmol} / \mathrm{L}$; orange lines, patients with plasma sclerostin levels of $>48.58 \mathrm{pmol} / \mathrm{L}$. Survival rates were compared with the logrank test 
Table 2 Univariate Cox regression analysis of risk factors for allcause mortality in kidney transplant recipients

\begin{tabular}{lllr}
\hline & HR & \multicolumn{1}{l}{$95 \%$ CI } & \multicolumn{1}{l}{$p$} \\
\hline Age & 1.074 & $1.049-1.098$ & $<0.0001$ \\
Sex & 1.608 & $0.929-2.783$ & 0.0896 \\
Cold ischemia time & 1.052 & $1.021-1.083$ & 0.0008 \\
Donor age & 1.017 & $1.000-1.035$ & 0.0506 \\
Time on dialysis & 1.005 & $0.998-1.012$ & 0.1710 \\
Time after transplantation & 1.002 & $0.999-1.005$ & 0.1528 \\
Total cholesterol & 0.997 & $0.992-1.002$ & 0.2861 \\
eGFR & 0.974 & $0.958-0.990$ & 0.0016 \\
Urine protein & 1.000 & $0.999-1.000$ & 0.6089 \\
Albumin & 0.340 & $0.133-0.873$ & 0.0249 \\
HbA1c & 1.458 & $1.166-1.823$ & 0.0009 \\
1,25(OH) ${ }_{2} \mathrm{D}$ & 1.001 & $0.996-1.006$ & 0.6877 \\
Calcium & 0.264 & $0.078-0.896$ & 0.0327 \\
Phosphate & 3.973 & $1.761-8.963$ & 0.0009 \\
iPTH & 1.000 & $0.998-1.002$ & 0.7863 \\
Sclerostin & 1.012 & $1.005-1.018$ & 0.0004 \\
\hline
\end{tabular}

Patients were followed for all-cause mortality for 3 years

eGFR, estimated glomerular filtration rate; HbA1c, hemoglobin A1c; iPTH, intact parathyroid hormone

above $48.58 \mathrm{pmol} / \mathrm{L}$ were significantly associated with all-cause mortality in renal transplant patients (Fig. 1; $p=0.0085$, log-rank test).

We built three multivariate Cox regression models by gradually adding confounding factors, which were parameters that were statistically significant predictors in the univariate analysis (Table 2). These three multivariate Cox regression models showed that sclerostin concentrations were independently associated with all-cause mortality in stable renal transplant recipients (Table 3; model A: hazard ratio, $1.013 ; 95 \%$ CI 1.004-1.021; $p=0.0052$; model B: hazard ratio, $1.011 ; 95 \%$ CI $1.002-1.020 ; p=0.0136$; model C: hazard ratio, $1.011 ; 95 \%$ CI 1.002-1.020; $p=0.0137)$.

Since some studies [17-19] reported that sclerostin concentrations in male CKD patients are higher than in female CKD patients, we performed an additional multivariate Cox regression model including additional sex as a confounding factor. This model likewise confirmed that sclerostin is an all-cause mortality risk factor after kidney transplantation (see supplementary Table 2). We also build another Cox regression model by adding time on dialysis and time after transplantation to model $\mathrm{C}$, sclerostin remain significant as an independent risk factor for all-cause mortality (see supplementary Table 3).
Table 3 Cox proportional hazards analysis of the relevant factors with all-cause mortality in renal transplant recipients

\begin{tabular}{|c|c|c|c|}
\hline & HR & $95 \% \mathrm{CI}$ & $p$ \\
\hline \multicolumn{4}{|l|}{ Model A } \\
\hline Age (> 59.5 years $)$ & 0.271 & $0.121-0.610$ & 0.0016 \\
\hline eGFR $\left(>49.5 \mathrm{~mL} / \mathrm{min} / 1.73 \mathrm{~m}^{2}\right)$ & 0.732 & $0.320-1.674$ & 0.4595 \\
\hline Albumin $(>4.45 \mathrm{~g} / \mathrm{dL})$ & 2.760 & $1.287-5.921$ & 0.0091 \\
\hline Sclerostin (pmol/L) & 1.013 & $1.004-1.021$ & 0.0052 \\
\hline \multicolumn{4}{|l|}{ Model B } \\
\hline Age $(>59.5$ years $)$ & 0.270 & $0.121-.0603$ & 0.0014 \\
\hline $\mathrm{eGFR}\left(>49.5 \mathrm{~mL} / \mathrm{min} / 1.73 \mathrm{~m}^{2}\right)$ & 0.695 & $0.304-1.589$ & 0.3885 \\
\hline Albumin $(>4.45 \mathrm{~g} / \mathrm{dL})$ & 2.670 & $1.220-5.842$ & 0.0140 \\
\hline Phosphate (>0.845 mmol/L) & 0.816 & $0.396-1.681$ & 0.5811 \\
\hline Calcium (> 2.435 mmol/L) & 1.660 & $0.789-3.494$ & 0.1819 \\
\hline Sclerostin (pmol/L) & 1.011 & $1.002-1.020$ & 0.0136 \\
\hline \multicolumn{4}{|l|}{ Model C } \\
\hline Age $(>59.5$ years $)$ & 0.262 & $0.112-0.611$ & 0.0019 \\
\hline eGFR (> $49.5 \mathrm{~mL} / \mathrm{min} / 1.73 \mathrm{~m} 2)$ & 0.645 & $0.277-1.507$ & 0.3115 \\
\hline Albumin $(>4.45 \mathrm{~g} / \mathrm{dL})$ & 2.756 & $1.245-6.097$ & 0.0124 \\
\hline Phosphate (>0.845 mmol/L) & 0.766 & $0.367-1.602$ & 0.4793 \\
\hline Calcium (> 2.435 mmol/L) & 1.651 & $0.774-3.522$ & 0.1945 \\
\hline Cold ischemia time $(>11.505 \mathrm{~h})$ & 1.082 & $0.515-2.273$ & 0.8344 \\
\hline $\mathrm{HbA} 1 \mathrm{c}(>6.05 \%)$ & 0.965 & $0.457-2.039$ & 0.9257 \\
\hline Sclerostin (pmol/L) & 1.011 & $1.002-1.020$ & 0.0137 \\
\hline
\end{tabular}

Multiple proportional hazards regression analyses (Cox regression; enter). Patients were followed for all-cause mortality for 3 years. Models A, B and C show that sclerostin levels are independently associated with all-cause mortality after adjustment for confounding variables

Subgroup analysis (Fig. 2) revealed that sclerostin is, in particular, an important all-cause mortality risk factor among male patients, among patients with lower GFR, among those with higher calcium, and among those with higher phosphate at study entry.

\section{Discussion}

This study demonstrated that elevated baseline plasma sclerostin is an independent risk factor of all-cause mortality in patients after kidney transplantation.

Patient demographics and relevant clinical and biochemical parameters indicate that our study population was representative for a typical European post-transplantation cohort. The findings of our study are thus of general applicability [20, 21].

In the non-transplanted CKD population, conflicting results concerning sclerostin-associated mortality risk were described [22-25]. Our study showed that elevated baseline plasma sclerostin is an independent risk factor of all-cause mortality in patients after kidney transplantation. There are at least two main reasons potentially explaining the 
Fig. 2 Association between sclerostin and all-cause mortality among subgroups. HRs for all-cause mortality by sex, eGFR, phosphate and calcium. albumin, phosphate, calcium, $\mathrm{HbAlc}$, and cold ischemia time Adjusted for age, eGFR, plasma

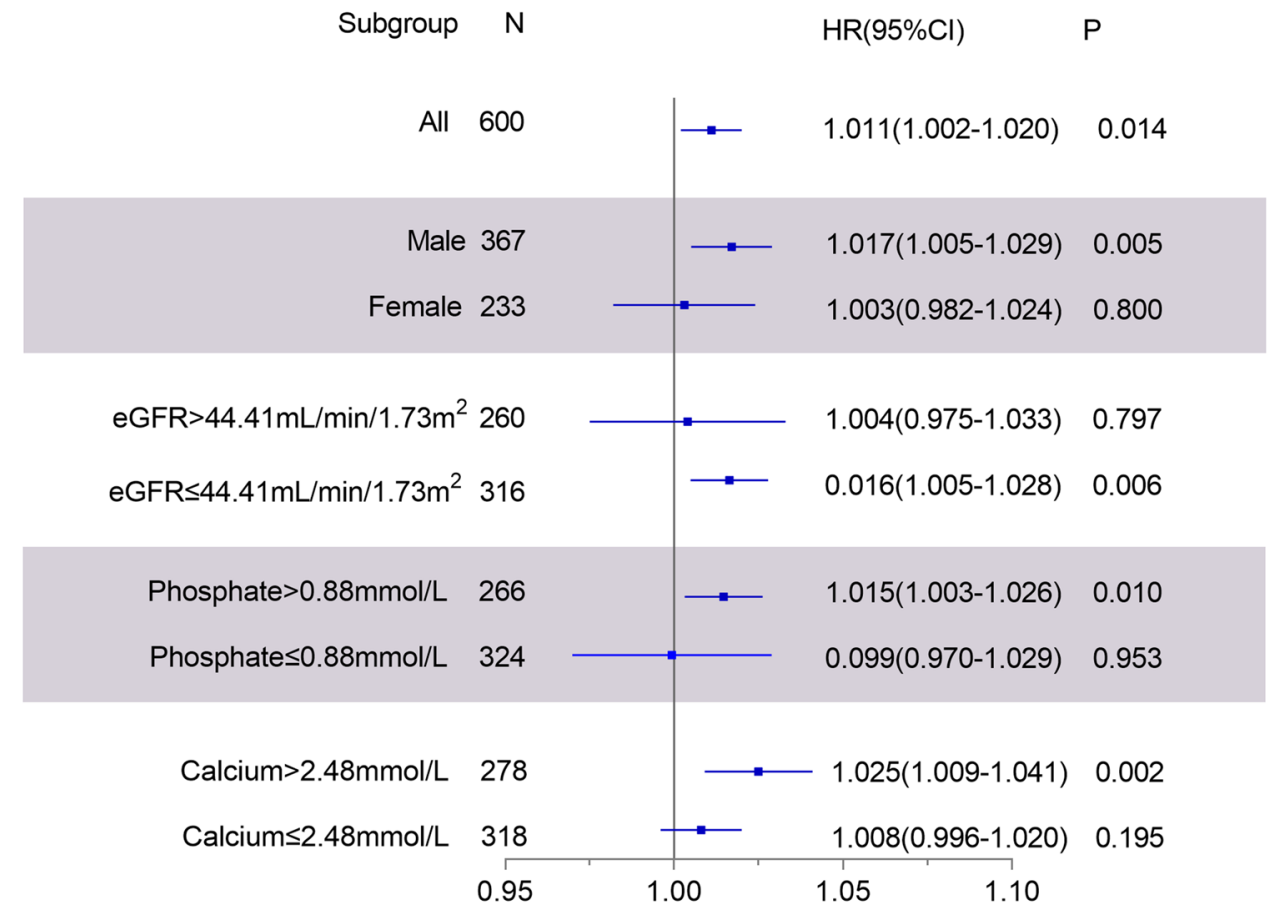

differences: Most of these studies [22-25] are substantially smaller than ours make any result subject to potential chance finding. In addition, the investigated populations were different to our cohort: CKD patients on hemodialysis or peritoneal dialysis, and non-dialysis CKD patients.

When analyzing male and female patients separately (Fig. 2), we found that sclerostin is associated with all-cause mortality just in male patients. This might be at least partially due to the fact that sclerostin concentrations are higher in male than female transplant recipients. Higher blood sclerostin concentrations in males were also reported in non-transplanted CKD patient cohorts [17-19]. Females might have lower sclerostin concentrations due to the estradiol mediated decreases in sclerostin seen in humans [26]. Sex differences with regard to all-cause mortality have also been described for the hormone relaxin in patients on hemodialysis [27].

Several other studies in dialysis cohorts analyzed the association of sclerostin with all-cause and cardiovascular mortality. These studies [23-25, 28-33], however, lead to conflicting data. So far, nine studies have analyzed the relationship between sclerostin and all-cause mortality in dialysis patients, five showed that sclerostin is associated with all-cause mortality [23-25, 32,33 , and four of them show no association [28-31]. Four of these studies also analyzed the relationship between sclerostin and cardiovascular mortality, three studies saw an association of sclerostin with cardiovascular mortality [23, 25, 28], but one study did not find this association [29]. Our study is the first to study the association of sclerostin with all-cause mortality in transplanted patients and clearly showed that sclerostin is an independent all-cause mortality risk factor in this population.
Fifty to 60 percent of deaths among kidney transplant recipients are directly attributable to cardiovascular disease, which has a reported incidence of approximately 1 per 100 personyears at risk $[34,35]$. The development of vascular calcification and arterial stiffness leads to an increased incidence of cardiovascular disease. Sclerostin is a soluble inhibitor of Wnt signaling pathway and Wnt signaling pathway is thought to be involved in the development of vascular calcification and cardiovascular disease [36].

It was suggested that sclerostin-as an inhibitor of Wnt signaling pathways might play a role in the development of aortic valve and vascular calcifications. A study conducted by Hampson et al. [37] supports this hypothesis. In adjusted linear regression analysis, sclerostin was positively associated with abdominal aortic calcification (AAC). Furthermore, Kuipers et al. [38] showed that increases by one standard deviation of sclerostin levels are associated with 1.61 times greater risk of coronary artery calcification. Sclerostin is an inhibitor of the LRP5/6 coreceptors and the intracellular part of LRP5/6 contains multiple phosphorylation sites, the phosphorylation of which is a key step in the initiation of the signal transduction via WNT/B-catenin signalling [39]. LRP6 was also found to limit the process of vascular calcification. Indeed, the conditional deletion of LRP6 in the vascular smooth muscle cell lineage increased aortic calcium content in diabetic LDLR-/- mice [40].

Our study demonstrated that sclerostin is an independent risk factor of all-cause mortality in kidney transplant recipients. Preclinical studies—see above—suggest that an inhibition of the transmission of the Wnt signaling pathway 
by inhibiting LRP5/6 co-receptors, resulting in increased vascular calcification and cardiovascular events. Whether this pathway might explain our findings needs to be explored in more detail.

A humanize monoclonal antibody targeting sclerostin is currently tested in clinical trials, Blosozumab (ClinicalTrials.gov Identifier: NCT01144377). It has been studied with regards to the treatment of osteoporosis in postmenopausal women with low bone density [41]. In addition, very recent research shows that SOST-Fc vaccination might be a therapeutic approach for preventing osteoporosis [42]. So far, it has not been established how anti-sclerostin antibodies affect vascular calcifications [43]. These studies will provide first clinical information's how sclerostin blocking antibodies might affect vascular calcification or vascular stiffness.

Several limitations should be taken into consideration when the results of this study are interpreted. Although we analyzed 600 patients, the sample size may be a limitation in our study, which might affect the results of the Cox regression analysis of multiple risk factors. We only have valid data on all-cause mortality. Data on specific reasons of death, such as cardiovascular mortality and cardiovascular events, however, were not available. Moreover, our study was a single-center study, thus center-specific effects could not be excluded. Thus, confirmation in an independent cohort is important.

Taken together, our study is the first to investigate the potential role of sclerostin in patients after kidney transplantation. Our data suggest that elevated baseline plasma sclerostin is an independent risk factor for all-cause mortality in patients after kidney transplantation. This is of particular clinical impact, since anti-sclerostin antibodies are currently under clinical investigation.

Acknowledgements S.Z. was financially supported by the China Scholarship Council.

Funding Open Access funding was provided by Projekt DEAL.

\section{Compliance with ethical standards}

Conflict of interest The authors declare no conflicts of interest.

Ethical statement The Ethics Committee approved the study (approval number 2012-327), and the research was performed in accordance with the Declaration of Helsinki. Study participants gave consent prior to participation.

Open Access This article is licensed under a Creative Commons Attribution 4.0 International License, which permits use, sharing, adaptation, distribution and reproduction in any medium or format, as long as you give appropriate credit to the original author(s) and the source, provide a link to the Creative Commons licence, and indicate if changes were made. The images or other third party material in this article are included in the article's Creative Commons licence, unless indicated otherwise in a credit line to the material. If material is not included in the article's Creative Commons licence and your intended use is not permitted by statutory regulation or exceeds the permitted use, you will need to obtain permission directly from the copyright holder. To view a copy of this licence, visit http://creativecommons.org/licenses/by/4.0/.

\section{References}

1. Suthanthiran M, Strom TB. Renal transplantation. N Engl J Med. 1994;331(6):365-76. https://doi.org/10.1056/NEJM19940811331 0606.

2. Regidor DL, Kovesdy CP, Mehrotra R, Rambod M, Jing J, McAllister CJ, et al. Serum alkaline phosphatase predicts mortality among maintenance hemodialysis patients. J Am Soc Nephrol. 2008;19(11):2193-203. https://doi.org/10.1681/Asn.2008010014.

3. Gutierrez OM, Mannstadt M, Isakova T, Rauh-Hain JA, Tamez $\mathrm{H}$, Shah A, et al. Fibroblast growth factor 23 and mortality among patients undergoing hemodialysis. N Engl J Med. 2008;359(6):584-92. https://doi.org/10.1056/Nejmoa0706130.

4. Floege J, Kim J, Ireland E, Chazot C, Drueke T, de Francisco A, et al. Serum iPTH, calcium and phosphate, and the risk of mortality in a European haemodialysis population. Nephrol Dial Transplant. 2011;26(6):1948-55. https://doi.org/10.1093/ndt/gfq219.

5. Peres LA, Percio PP. Mineral and bone disorder and vascular calcification in patients with chronic kidney disease. J Bras Nefrol. 2014;36(2):201-7.

6. Weidauer SE, Schmieder P, Beerbaum M, Schmitz W, Oschkinat $\mathrm{H}$, Mueller TD. NMR structure of the Wnt modulator protein sclerostin. Biochem Biophys Res Commun. 2009;380(1):160-5. https://doi.org/10.1016/j.bbrc.2009.01.062.

7. Balemans W, Ebeling M, Patel N, Van Hul E, Olson P, Dioszegi $\mathrm{M}$, et al. Increased bone density in sclerosteosis is due to the deficiency of a novel secreted protein (SOST). Hum Mol Genet. 2001;10(5):537-43. https://doi.org/10.1093/Hmg/10.5.537.

8. Drake MT, Khosla S. Hormonal and systemic regulation of sclerostin. Bone. 2017;96:8-17. https://doi.org/10.1016/j. bone.2016.12.004.

9. Kanbay M, Siriopol D, Saglam M, Kurt YG, Gok M, Cetinkaya $\mathrm{H}$, et al. Serum sclerostin and adverse outcomes in nondialyzed chronic kidney disease patients. J Clin Endocrinol Metab. 2014;99(10):E1854-E18611861. https://doi.org/10.1210/ jc. 2014-2042.

10. Abeling T, Scheffner I, Karch A, Broecker V, Koch A, Haller H, et al. Risk factors for death in kidney transplant patients: analysis from a large protocol biopsy registry. Nephrol Dial Transplant. 2018. https://doi.org/10.1093/ndt/gfy131.

11. Schold JD, Buccini LD, Reese PP, Poggio ED, Goldfarb DA. Effect of dialysis initiation for preemptively listed candidates in the revised kidney allocation policy. Am J Transplant. 2014;14(12):2855-60. https://doi.org/10.1111/ajt.12957.

12. Guijarro C, Massy ZA, Wiederkehr MR, Ma JZ, Kasiske BL. Serum albumin and mortality after renal transplantation. Am J Kidney Dis. 1996;27(1):117-23.

13. Moore J, Tomson CR, Tessa Savage M, Borrows R, Ferro CJ. Serum phosphate and calcium concentrations are associated with reduced patient survival following kidney transplantation. Clin Transpl. 2011;25(3):406-16. https://doi.org/10.111 1/j.1399-0012.2010.01292.x.

14. Debout A, Foucher Y, Trebern-Launay K, Legendre C, Kreis H, Mourad G, et al. Each additional hour of cold ischemia time significantly increases the risk of graft failure and mortality following renal transplantation. Kidney Int. 2015;87(2):343-9. https:// doi.org/10.1038/ki.2014.304.

15. Hocher B, Oberthur D, Slowinski T, Querfeld U, Schaefer F, Doyon A, et al. Modeling of oxidized PTH (oxPTH) and nonoxidized PTH (n-oxPTH) receptor binding and relationship of 
oxidized to non-oxidized PTH in children with chronic renal failure, adult patients on hemodialysis and kidney transplant recipients. Kidney Blood Press Res. 2013;37(4-5):240-51. https://doi. org/10.1159/000350149.

16. Hocher B, Ziebig R, Altermann C, Krause R, Asmus G, Richter $\mathrm{CM}$, et al. Different impact of biomarkers as mortality predictors among diabetic and nondiabetic patients undergoing hemodialysis. J Am Soc Nephrol. 2003;14(9):2329-37.

17. Pietrzyk B, Wyskida K, Ficek J, Kolonko A, Ficek R, Wiecek A, et al. Relationship between plasma levels of sclerostin, calciumphosphate disturbances, established markers of bone turnover, and inflammation in haemodialysis patients. Int Urol Nephrol. 2019;51(3):519-26. https://doi.org/10.1007/s11255-018-2050-3.

18. Thambiah S, Roplekar R, Manghat P, Fogelman I, Fraser WD, Goldsmith D, et al. Circulating sclerostin and Dickkopf-1 (DKK1) in predialysis chronic kidney disease (CKD): relationship with bone density and arterial stiffness. Calcif Tissue Int. 2012;90(6):473-80. https://doi.org/10.1007/s00223-012-9595-4.

19. Pelletier S, Dubourg L, Carlier MC, Hadj-Aissa A, Fouque D. The relation between renal function and serum sclerostin in adult patients with CKD. Clin J Am Soc Nephrol. 2013;8(5):819-23. https://doi.org/10.2215/CJN.07670712.

20. Evenepoel P, Goffin E, Meijers B, Kanaan N, Bammens B, Coche E, et al. Sclerostin serum levels and vascular calcification progression in prevalent renal transplant recipients. J Clin Endocrinol Metab. 2015;100(12):4669-766. https://doi.org/10.1210/ jc.2015-3056.

21. Hsu BG, Liou HH, Lee CJ, Chen YC, Ho GJ, Lee MC. Serum sclerostin as an independent marker of peripheral arterial stiffness in renal transplantation recipients: a cross-sectional study. Medicine (Baltimore). 2016;95(15):e3300. https://doi.org/10.1097/ MD.0000000000003300.

22. Desjardins L, Liabeuf S, Oliveira RB, Louvet L, Kamel S, Lemke $\mathrm{HD}$, et al. Uremic toxicity and sclerostin in chronic kidney disease patients. Nephrologie Therapeutique. 2014;10(6):463-70. https:// doi.org/10.1016/j.nephro.2014.04.002.

23. Goncalves FLC, Elias RM, dos Reis LM, Graciolli FG, Zampieri FG, Oliveira RB, et al. Serum sclerostin is an independent predictor of mortality in hemodialysis patients. BMC Nephrol. 2014. https://doi.org/10.1186/1471-2369-15-190 (Artn 190).

24. Viaene L, Behets GJ, Claes K, Meijers B, Blocki F, Brandenburg V, et al. Sclerostin: another bone-related protein related to all-cause mortality in haemodialysis? Nephrol Dial Transpl. 2013;28(12):3024-30. https://doi.org/10.1093/ndt/gft039.

25. Drechsler C, Evenepoel P, Vervloet MG, Wanner C, Ketteler M, Marx N, et al. High levels of circulating sclerostin are associated with better cardiovascular survival in incident dialysis patients: results from the NECOSAD study. Nephrol Dial Transpl. 2015;30(2):288-93. https://doi.org/10.1093/ndt/gfu301.

26. Singhal V, Ackerman KE, Bose A, Flores LPT, Lee H, Misra M. Impact of route of estrogen administration on bone turnover markers in oligoamenorrheic athletes and its mediators. J Clin Endocrinol Metab. 2019;104(5):1449-588. https://doi.org/10.1210/ jc. 2018-02143.

27. Hocher B, Ziebig R, Krause R, Asmus G, Neumayer HH, Liefeldt $\mathrm{L}$, et al. Relaxin is an independent risk factor predicting death in male patients with end-stage kidney disease. Circulation. 2004;109(19):2266-8. https://doi.org/10.1161/01.CIR.00001 28598.72920.B5.

28. Kalousova M, Dusilova-Sulkova S, Kubena AA, Zakiyanov O, Tesar V, Zima T. Sclerostin levels predict cardiovascular mortality in long-term hemodialysis patients: a prospective observational cohort study. Physiol Res. 2019;68(4):547-58. https://doi. org/10.33549/physiolres.934034.

29. Sato M, Hanafusa N, Kawaguchi H, Tsuchiya K, Nitta K. A prospective cohort study showing no association between serum sclerostin level and mortality in maintenance hemodialysis patients. Kidney Blood Press Res. 2018;43(3):1023-33. https:// doi.org/10.1159/000490824.

30. Delanaye P, Krzesinski JM, Warling X, Moonen M, Smelten N, Medart L, et al. Clinical and biological determinants of sclerostin plasma concentration in hemodialysis patients. Nephron Clin Pract. 2014;128(1-2):127-34. https://doi.org/10.1159/000366449.

31. Nowak A, Artunc F, Serra AL, Pollock E, Krayenbuhl PA, Muller $\mathrm{C}$, et al. Sclerostin quo vadis? Is this a useful long-term mortality parameter in prevalent hemodialysis patients? Kidney Blood Press Res. 2015;40(3):266-76. https://doi.org/10.1159/000368502.

32. Jean G, Chazot C, Bresson E, Zaoui E, Cavalier E. High serum sclerostin levels are associated with a better outcome in haemodialysis patients. Nephron. 2016;132(3):181-90. https://doi. org/10.1159/000443845.

33. Lips L, de Roij van Zuijdewijn CLM, Ter Wee PM, Bots ML, Blankestijn PJ, van den Dorpel MA, et al. Serum sclerostin: relation with mortality and impact of hemodiafiltration. Nephrol Dial Transpl. 2017;32(7):1217-23. https://doi.org/10.1093/ndt/gfw24 6.

34. Yeo FE, Villines TC, Bucci JR, Taylor AJ, Abbott KC. Cardiovascular risk in stage 4 and 5 nephropathy. Adv Chronic Kidney Dis. 2004;11(2):116-33.

35. Ojo AO. Cardiovascular complications after renal transplantation and their prevention. Transplantation. 2006;82(5):603-11. https:// doi.org/10.1097/01.tp.0000235527.81917.fe.

36. Ress C, Paulweber M, Goebel G, Willeit K, Rufinatscha K, Strobl A, et al. Circulating Wnt inhibitory factor 1 levels are associated with development of cardiovascular disease. Atherosclerosis. 2018;273:1-7. https://doi.org/10.1016/j.atherosclerosis .2018.03.045.

37. Hampson G, Edwards S, Conroy S, Blake GM, Fogelman I, Frost ML. The relationship between inhibitors of the Wnt signalling pathway (Dickkopf-1(DKK1) and sclerostin), bone mineral density, vascular calcification and arterial stiffness in post-menopausal women. Bone. 2013;56(1):42-7. https://doi.org/10.1016/j. bone.2013.05.010.

38. Kuipers AL, Miljkovic I, Carr JJ, Terry JG, Nestlerode CS, $\mathrm{Ge}$ YR, et al. Association of circulating sclerostin with vascular calcification in Afro-Caribbean men. Atherosclerosis. 2015;239(1):218-23. https://doi.org/10.1016/j.atherosclerosis .2015.01.010.

39. Niehrs C, Shen J. Regulation of Lrp6 phosphorylation. Cell Mol Life Sci. 2010;67(15):2551-622. https://doi.org/10.1007/s0001 8-010-0329-3.

40. Cheng SL, Ramachandran B, Behrmann A, Shao JS, Mead M, Smith C, et al. Vascular smooth muscle LRP6 limits arteriosclerotic calcification in diabetic LDLR-/- mice by restraining noncanonical Wnt signals. Circ Res. 2015;117(2):142-56. https://doi. org/10.1161/CIRCRESAHA.117.306712.

41. Recker RR, Benson CT, Matsumoto T, Bolognese MA, Robins DA, Alam J, et al. A randomized, double-blind phase 2 clinical trial of blosozumab, a sclerostin antibody, in postmenopausal women with low bone mineral density. J Bone Miner Res. 2015;30(2):216-24. https://doi.org/10.1002/jbmr.2351.

42. Wang FS, Wu RW, Lain WS, Tsai TC, Chen YS, Sun YC, et al. Sclerostin vaccination mitigates estrogen deficiency induction of bone mass loss and microstructure deterioration. Bone. 2018;112:24-34. https://doi.org/10.1016/j.bone.2018.04.007.

43. Pietrzyk B, Smertka M, Chudek J. Sclerostin: Intracellular mechanisms of action and its role in the pathogenesis of skeletal and vascular disorders. Adv Clin Exp Med. 2017;26(8):1283-91. https ://doi.org/10.17219/acem/68739.

Publisher's Note Springer Nature remains neutral with regard to jurisdictional claims in published maps and institutional affiliations. 